Nadira Dina Mahyuna

p-ISSN 2621-3184 ; e-ISSN 2621-4032

doi: 10.36387/jifi.v3i2.579

\title{
PEMBUATAN LULUR KRIM DARI LIMBAH KULIT BAWANG MERAH (Allium cepa L) DAN CANGKANG TELUR AYAM DENGAN EMULGATOR SPAN-TWEEN 80
}

\author{
Nadira Dina Mahyuna, Rina Kurniaty ${ }^{*}$ \\ Akademi Farmasi Yayasan Pendidikan Masyarakat Aceh Mandiri Persada \\ Banda Aceh \\ *: rinaothee@gmail.com
}

\begin{abstract}
ABSTRAK
Lulur krim merupakan body scrub yang mengandung bahan agak kasar dengan bahan-bahan dasar krim. Pada penelitian ini digunakan ekstrak kulit bawang merah (Allium cepa L.) dan serbuk cangkang telur ayam dengan tujuan untuk mengetahui pada konsentrasi emulgator (Span-Tween 80) berapa yang dapat memberikan stabilitas lulur krim yang paling baik. Ekstrak kulit bawang merah dibuat dengan cara maserasi menggunakan pelarut metanol sampai di peroleh ekstrak cair, kemudian dipekatkan menggunakan vacum rotary evaporator hingga di peroleh ekstrak kental. 3 variasi konsentrasi dari emulgator yang digunakan tiap $100 \mathrm{~g}$ formulasi lulur krim, yaitu 1\% (F1), 2\% (F2), dan 3\% (F3). Evaluasi lulur krim meliputi uji organoleptis, uji homogenitas, uji daya sebar, uji tipe emulsi dan pengukuran $\mathrm{pH}$. Hasil evaluasi menunjukkan bahwa ketiga formulasi lulur krim homogen dan uji tipe emulsi setelah dilakukan pengeceran menggunakan aquadest memiliki tipe M/A. Hasil pengujian daya sebar menunjukkan formula lulur krim F2 memiliki daya sebar yang lebih besar dibandingkan dengan F1 dan F3. Emulgator span-tween 80 dengan konsentrasi 2\% menghasilkan stabilitas yang paling baik untuk formulasi lulur krim.
\end{abstract}

Kata kunci: kulit bawang merah, cangkang telur ayam, emulgator, span-tween 80 , lulur krim.

ABSTRACT

Cream scrub is a body scrub that contains slightly harsh ingredients with creambased ingredients. In this study, onion extract (Allium cepa L.) and chicken eggshell powder were used in order to determine which emulgator concentration (SpanTween 80 ) could provide the best stability of cream scrub. Onion extract was made by maceration using methanol solvent to obtain liquid extract, afterward concentrated using vacuum rotary evaporator until a thick extract was obtained. There were 3 concentration variation of emulgator used for each $100 \mathrm{~g}$ of cream scrub formulation, namely 1\% (F1), 2\% (F2), and 3\% (F3). Evaluation of cream scrub included organoleptic test, homogeneity test, dispersion test, emulsion type test and $\mathrm{pH}$ measurement. The results showed that all three cream scrub formulations were homogeneous and the cream scrub had M/A emulsion type. The results of dispersion test showed that $\mathrm{F} 2$ cream scrub had greater dispersibility than $\mathrm{F} 1$ and F3. Emulgator span-tween 80 with a concentration of $2 \%$ provided the best stability for cream scrub formulations.

Key words: onion, chicken eggshell, emulgator, span-tween 80, cream scrub 
Nadira Dina Mahyuna

p-ISSN 2621-3184 ; e-ISSN 2621-4032

doi: 10.36387/jifi.v3i2.579

\section{PENDAHULUAN}

Limbah kulit bawang merah dan cangkang telur ayam rash, yang dihasilkan dari industri rumah tangga dan rumah makan sebagian besar masih belum dapat dimanfaatkan dengan baik. Hal ini sangat disayangkan, karena pada kulit bawang merah dan cangkang telur ayam rash ternyata banyak sekali manfaat yang tidak diketahui oleh semua orang. Salah satunya dapat digunakan untuk kecantikan. Lulur adalah salah satu sediaan kosmetik tradisional yang dapat digunakan untuk mengangkat sel kulit mati, kotoran dan membuka pori-pori pada kulit, sehingga pertukaran udara bebas dan kulit tubuh menjadi lebih cerah dan putih. Lulur terbagi beberapa bentuk sediaan, salah satunya lulur krim (body scrub) yang mengandung bahan agak kasar, dengan bahan-bahan dasar krim pembersih kulit dengan kandungan lemak penyegar, butiran-butiran kasar sebagai pengampelas (obrasiver) untuk mengangkat sel-sel kulit mati dari epidermis. ${ }^{1,2}$

Bawang merah (Allium cepa L.) merupakan salah satu tanaman hortikultura yang banyak dikonsumsi manusia sebagai campuran bumbu masak setelah cabe dan dijual bisa dalam bentuk olahan, seperti ekstrak bawang merah, bubuk, minyak atsiri, bawang goreng dan dapat digunakan sebagai bahan obat untuk menurunkan kadar kolesterol, gula darah, mencegah penggumpalan darah, menurunkan tekanan darah serta memperlancar aliran darah. ${ }^{3}$ Hasil penelitian dari Benitez (Cranfield University, Inggris), bahwa kulit coklat bawang dapat digunakan sebagai bahan fungsional tinggi serat (terutama jenis non larut) dan senyawa fenolik, seperti kuersetin dan zat atioksidan yang mengandung suatu pigmen tanaman yang bisa membantu mengurangi tekanan darah dan mencegah penyumbatan pembuluh darah, selain itu juga memiliki efek anti-inflamasi yang dapat membantu penyembuhan penyakit peradangan. ${ }^{4}$ Kulit bawang merah juga mengandung senyawa kimia yang berpotensi sebagai antioksidan yaitu flavonoid, yang dapat mencegah berkembangnya radikal bebas di dalam tubuh sekaligus memperbaiki sel-sel tubuh 
yang rusak, dan selain itu kulit bawang merah juga diyakini memiliki aktivitas tabir surya. $^{5}$

Telur ayam merupakan salah satu produk peternakan yang cukup populer dan banyak dikonsumsi. Berdasarkan data statistik, konsumsi telur ayam di Indonesia bertumbuh sebesar $1,61 \%$ dalam rentang waktu tahun 2009-2013. Hal ini karena telur ayam merupakan komoditas yang relatif terjangkau dan memiliki gizi yang tinggi sehingga diminati oleh masyarakat. ${ }^{6}$

Cangkang telur ayam memiliki komposisi utama $\mathrm{CaCO} 3$ dan terdiri dari 4 lapisan berbeda yang dapat digambarkan sebagai struktur terorganisasi dengan baik, yaitu dari dalam ke luar lapisan membran, lapisan mamilary, lapisan busa, dan lapisan kurtikula. Cangkang telur ayam yang membungkus telur memiliki berat $9-12 \%$ dari berat telur total, mengandung $94 \%$ kalsium karbonat, $1 \%$ kalium phospat dan $1 \%$ magnesium karbonat. Kalsium yang terdapat pada cangkang telur juga berfungsi untuk meningkatkan densitas mineral dalam tulang bagi penderita osteoporosis, dan bioavabilitas kalsium dari cangkang telur ini cukup tinggi, yaitu sebesar $93.80 \%$. $^{7}$
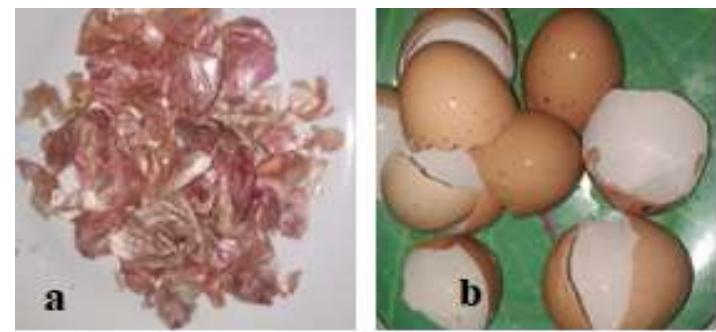

Gambar 1. (a) Kulit Bawang Merah dan (b) Cangkang Telur Ayam

\section{METODE PENELITIAN}

\section{Alat dan Bahan}

Alat yang digunakan yaitu timbangan digital, spatula, wadah untuk maserasi, batang pengaduk, corong kaca, cawan porselen, lumpang, alu, $\mathrm{pH}$ indikator universal, mesh 80, gelas ukur, beaker glass.

Bahan-bahan yang digunakan yaitu kulit bawang merah (Allium cepa L), cangkang telur ayam rash, asam stearat, Span-Tween 80, propilenglikol, setil alkohol, paraffin cair, adepslanae, metil paraben, propil paraben dan aquadest.

\section{Proses Pengolahan Kulit Bawang}

Merah dan Cangkang Telur Ayam

Kulit bawang merah dicuci dengan air yang mengalir sampai bersih, kemudian ditiriskan, 
Nadira Dina Mahyuna

p-ISSN 2621-3184 ; e-ISSN 2621-4032

doi: 10.36387/jifi.v3i2.579

selanjutnya pengeringan selama 2-3

hari tanpa terkena cahaya matahari langsung. ${ }^{5}$

Cangkang telur ayam dicuci dengan air sampai bersih, kemudian dilakukan perebusan selama 15 menit untuk menghilangkan bakteri yang melekat pada cangkang telur. Selanjutnya cangkang telur dioven selama 2 jam pada suhu $60^{\circ} \mathrm{C}$, dihaluskan sampai menjadi serbuk dan diayak dengan mesh $80 .^{7}$

\section{Proses Ekstraksi Kulit Bawang} Merah

Kulit bawang merah sejumlah 300 g dimasukkan kedalam wadah maserasi, ditambahkan pelarut metanol sebanyak 3 L, ditutup dan didiamkan selama 3 hari, sambil diaduk berulang-ulang, kemudian saring (Filtrat 1). Hasil residu diremaserasi kembali dengan penambahan pelarut metanol sebanyak 1 L selama 2 hari (Filtrat 2). Filtrat (1 dan 2) yang diperoleh 2,75 L dipekatkan dengan menggunakan vacum rotary evaporator pada suhu $65^{\circ} \mathrm{C}$, hingga di peroleh $39 \mathrm{~g}$ ekstrak pekat kulit bawang merah. ${ }^{8}$

\section{Skrining Fitokimia Ekstrak Kulit}

\section{Bawang Merah}

\section{$\underline{\text { 1. Uji Alkaloid }}$}

a. Pereaksi Dragendorf

$1 \mathrm{~mL}$ ekstrak +2 tetes pereaksi

Dragendorf menghasilkan kekeruhan dan endapan warna jingga

b. Pereaksi Bouchardat

$1 \mathrm{~mL}$ ekstrak +2 tetes pereaksi

bouchardat menghasilkan warna merah kecoklatan.

c. Pereaksi Wagner

$1 \mathrm{~mL}$ ekstrak +2 tetes pereaksi mayeR menghasilkan warna putih keruh, +2 tetes pereaksi wagner menghasilkan warna kuning kemerahan.

\section{Uji Saponin}

$1 \mathrm{~mL}$ ekstrak ditambahkan $1 \mathrm{~mL}$ air panas kemudian didinginkan lalu di kocok selama 10 menit menghasilkan buih yang stabil.

\section{Uji Tanin}

$1 \mathrm{~mL}$ ekstrak + air panas $1 \mathrm{~mL}$ dan 2 tetes gelatin $1 \%$, akan membentuk endapan putih keruh.

\section{Uji Polifenol}

$1 \mathrm{~mL}$ ekstrak +3 tetes $\mathrm{FeCl}_{3} 10 \%$, dikocok menghasilkan warna hijau, merah, ungu, biru atau hitam.

\section{Uji Kuinon}


Jurnal Insan Farmasi Indonesia, 3(2) Desember 2020 (344-353)

Nadira Dina Mahyuna

p-ISSN 2621-3184 ; e-ISSN 2621-4032

doi: 10.36387/jifi.v3i2.579

$1 \mathrm{~mL}$ ekstrak + air panas dan 2 tetes

$\mathrm{KOH} \mathrm{5 \%} \mathrm{menghasilkan} \mathrm{warna} \mathrm{merah.}$

\section{Uji Flavonoid}

$1 \mathrm{~mL}$ ekstrak +3 tetes $\mathrm{HCl}$ pekat, dipanaskan selama 15 menit di atas penangas, terbentuknya warna merah.

\section{Uji Steroid}

$1 \mathrm{~mL}$ ekstrak +3 tetes $\mathrm{CH}_{3} \mathrm{COOH}$ dan

2 tetes $\mathrm{H}_{2} \mathrm{SO}_{4} \quad \mathrm{P}$, dikocok jika menghasilkan warna biru atau hijau.

\section{$\underline{\text { 8. Uji Terpenoid }}$}

$1 \mathrm{~mL}$ ekstrak +3 tetes $\mathrm{CH}_{3} \mathrm{COOH}$ dan 2 tetes $\mathrm{H}_{2} \mathrm{~S}_{4} \quad \mathrm{P}$, dikocok menghasilkan warna merah atau ungu.

\section{Identifikasi senyawa yang terkandung dalam Serbuk Cangkang Telur Ayam \\ 1. Identifikasi Senyawa Aluminium}

Serbuk cangkang $+1 \mathrm{~mL}$ larutan $\mathrm{NaOH} \quad 40 \%$ di kocok hingga membentuk 2 fase, ditambahkan 1 $\mathrm{mL} \mathrm{H}_{2} \mathrm{SO}_{4}$ di kocok lagi, saring, kemudian ditambahkan 3 tetes larutan $\mathrm{NaOH} 6 \mathrm{M}$ menghasilkan endapan putih.

\section{Identifikasi senyawa Kalsium}

Serbuk cangkang $+1 \mathrm{~mL}$ HCL pekat, kemudian dipanaskan menghasilkan warna merah bata.

3. Identifikasi Senyawa Magnesium

Serbuk cangkang $+1 \mathrm{~mL}$ HCL $6 \mathrm{~N}$, diamkan, diencerkan 4 kali, akan terjadi perubahan warna, ditambahkan 2 tetes $\mathrm{NaOH} \quad 6 \mathrm{M}$ warna yang lebih pekat, ditambahkan 2 tetes larutan $\mathrm{Na}_{2} \mathrm{SO}_{4}$, jika membentuk endapan putih maka positif magnesium.

Tabel 1. Rancangan Formulasi Lulur Krim Ekstrak Kulit Bawang Merah dan Serbuk Cangkang Telur Ayam

\begin{tabular}{|c|c|c|c|}
\hline \multirow{2}{*}{ Bahan } & \multicolumn{3}{|c|}{$\begin{array}{c}\text { Formulasi Lulur Krim } \\
(\% \mathrm{~b} / \mathrm{v})\end{array}$} \\
\hline & F1 & F2 & F3 \\
\hline $\begin{array}{l}\text { Serbuk cangkang } \\
\text { telur ayam }\end{array}$ & 5,5 & 5,5 & 5,5 \\
\hline $\begin{array}{c}\text { Ekstrak kulit } \\
\text { bawang merah }\end{array}$ & 1 & 1 & 1 \\
\hline Asam stearat & 5 & 5 & 5 \\
\hline Setil alkohol & 3 & 3 & 3 \\
\hline Span 80 & 1 & 2 & 3 \\
\hline Tween 80 & 1 & 2 & 3 \\
\hline Propilenglikol & 0,2 & 0,2 & 0,2 \\
\hline Paraffin Cair & 5 & 5 & 5 \\
\hline Adepslanae & 5 & 5 & 5 \\
\hline Metil Paraben & 0,1 & 0,1 & 0,1 \\
\hline Propil paraben & 0,05 & 0,05 & 0,05 \\
\hline Aquadest ad & 100 & 100 & 100 \\
\hline
\end{tabular}

\section{Keterangan:}

F1, Lulur krim ekstrak kulit bawang merah dan serbuk cangkang telur ayam, dengan konsentrasi emulgator span- tween 80 dengan konsentrasi $1 \%$.

F2, Lulur krim ekstrak kulit bawang merah dan serbuk cangkang telur ayam, dengan konsentrasi emulgator span-tween 80 dengan konsentrasi $2 \%$.

F3, Lulur krim ekstrak kulit bawang merah dan serbuk cangkang telur ayam, dengan konsentrasi emulgator span-tween 80 dengan konsentrasi 3\%.

Pembuatan Lulur Krim 
Adepslanae, setil alkohol, asam stearat, span 80 , dan propil paraben (fase minyak) dilebur pada suhu $70^{\circ} \mathrm{C}$. Metil paraben dilarutkan dalam air panas, kemudian ditambahkan propilenglikol, paraffin cair, dan tween 80 (fase air). Massa lulur krim dibuat dengan cara mencampurkan fase minyak dan fase air, sambil digerus kuat sampai homogen, kemudian ditambahkan ekstrak kulit bawang merah dan serbuk cangkang telur ayam, aduk sampai homogen dan menjadi krim. ${ }^{2}$

\section{Uji Evaluasi Lulur Krim}

\section{Uji Organoleptis}

Dilakukan pengamatan organoleptis yang meliputi warna, bentuk, bau dan tekstur secara visual dari formulasi lulur krim F1, F2 dan F3 dengan ekstrak kulit bawang merah dan serbuk cangkang ayam.

2. Uji Homogenitas

0,5 g lulur krim dioleskan pada kaca objek, kemudian diamati susunan yang homogen atau tidak homogen serta tidak terlihat adanya partikel-partikel asing. ${ }^{8}$

\section{3. $\mathrm{Uji} \mathrm{pH}$}

$0,5 \mathrm{~g}$ lulur krim dalam beaker glass, diencerkan dengan air $5 \mathrm{~mL}$, kemudian di cek $\mathrm{pH}$ sesuai dengan warna $\mathrm{pH}$ indikator yang tertera. ${ }^{9}$

4. Uji Daya Sebar

0,5 g lulur krim diletakkan diantara lempeng kaca, dimana lempeng sebelah atas dalam interval waktu tertentu dibebani anak timbangan diatasnya. Permukaan pada penyebaran lulur krim yang dihasilkan, dengan meningkatkan beban merupakan karakteristik daya sebar. ${ }^{10}$

\section{Uji Tipe Emulsi}

1 g lulur krim dalam beaker glass, diencerkan dengan sedikit air. Jika dapat diencerkan maka tipe krim adalah minyak dalam air (M/A). ${ }^{11}$

\section{HASIL DAN PEMBAHASAN}

Hasil skrining fitokimia dari ekstrak kulit bawang merah menunjukkan bahwa ada beberapa senyawa metabolit sekunder yang positif, berdasarkan perubahan warna dari ekstrak setelah diteteskan pereaksi, yaitu senyawa alkaloid, tanin, polifenol, kuinon, flavonoid, dan terpenoid (Tabel 2).

Identifikasi untuk senyawa yang terkandung dalam cangkang telur ayam dengan menggunakan 
Jurnal Insan Farmasi Indonesia, 3(2) Desember 2020 (344-353)

Nadira Dina Mahyuna

p-ISSN 2621-3184 ; e-ISSN 2621-4032

doi: 10.36387/jifi.v3i2.579

beberapa pereaksi pada Tabel 3, sedangkan senyawa aluminium menunjukkan hasil positif adanya negatif pada cangkang telur ayam. senyawa kalsium dan magnesium,

Tabel 2. Hasil Skrining Fitokimia

\begin{tabular}{lllc}
\hline \multicolumn{1}{c}{ Uji } & \multicolumn{1}{c}{ Pereaksi } & \multicolumn{1}{c}{ Hasil } & Ket \\
\hline \multirow{2}{*}{ Alkaloid } & Dragendorf & Endapan coklat jingga & + \\
& Bourchardat & merah kecoklatan & + \\
& Mayer dan Wagner & warna kemerahan & + \\
Saponin & Air panas & Tidak terbentuk gelembung & - \\
Tanin & Air panas dan Gelatin 1\% & Larutan putih keruh & + \\
Polifenol & $\mathrm{FeCl}_{3}$ & Larutan biru & + \\
Kuinon & Air panasdan KOH 5\% & Larutan merah & + \\
Flavonoid & $\mathrm{HCL}$ pekat & Larutan merah & - \\
Steroid & $\mathrm{CH} 3 \mathrm{COOH}$ dan H2SO4 pekat & Tidak terbentuk larutan hijau & + \\
Terpenoid & $\mathrm{CH}$ COOH dan $\mathrm{H} 2 \mathrm{SO} 4$ pekat & Terbentuk larutan merah & + \\
\hline
\end{tabular}

Tabel 3. Hasil Identifikasi Senyawa Yang Terkandung dalam Cangkang Telur Ayam

\begin{tabular}{cccc}
\hline Uji & Pereaksi & Hasil & Ket \\
\hline \multirow{2}{*}{ Aluminium } & $\mathrm{NaOH} 40 \%, \mathrm{H}_{2} \mathrm{SO}_{4}$, & Tidak terbentuk endapan putih & - \\
Kalsium & dan $\mathrm{NaOH} 6 \mathrm{M}$ & Terbentuk warna merah bata & + \\
MCL pekat & Terbentuk endapan putih & + \\
\hline
\end{tabular}

\section{Hasil Evaluasi Lulur Krim}

Uji organoleptis berdasarkan pada tabel 4, menunjukkan bahwa F1, F2, dan F3 lulur krim memiliki warna kecoklatan dengan bentuk semi padat, bertekstur kental dengan butiranbutiran halus dari serbuk cangkang telur dan berbau khas. Lulur krim $(\mathrm{F} 1, \mathrm{~F} 2$ dan $\mathrm{F} 3)$ dengan variasi konsentrasi emulgator span-tween 80 , yaitu $1 \%, 2 \%$, dan $3 \%$ tidak menunjukkan adanya pengaruh pengemulsi nonionik terhadap perubahan organoleptis dari segi bentuk, warna dan bau dari lulur krim yang dibuat. Uji homogenitas pada lulur krim (F1, F2 dan F3), memiliki susunan yang homogen, dimana butiran-butiran halus dari serbuk cangkang telur ayam dapat tercampur homogen dengan bahan lain. Hasil uji pH pada lulur krim (F1, F2 dan F3) selama penyimpanan 24 memiliki $\mathrm{pH}$ 5. Dimana $\mathrm{pH}$ yang diperoleh lulur 
krim masih berada dalam range $\mathrm{pH}$ kulit yang diinginkan, yaitu 4,5-6,5. Pengukuran $\mathrm{pH}$ ini bertujuan untuk mengetahui tingkat keasaman dan kebasaan dari 3 formula lulur krim yang dibuat. Jika $\mathrm{pH}$ dari lulur krim bersifat basa (tidak masuk dalam rentang $\mathrm{pH}$ 4,5-6,5) dapat mengakibatkan kulit terasa licin dan cepat kering, serta mempengaruhi elastisitas dari kulit. Jika lulur krim bersifat asam, berada dibawah range $\mathrm{pH}$ kulit juga dapat mengakibatkan kulit mudah teriritasi. ${ }^{2}$

Hasil uji daya sebar pada lulur krim yang mengandung ekstrak kulit bawang merah dan serbuk cangkang telur ayam rash berdasarkan tabel 5, menunjukkan F2 memiliki daya sebar yang lebih besar yaitu 2,75 cm dibandingkan F1 dengan daya sebar 1,9 cm dan F3 dengan daya sebar 2,6 $\mathrm{cm}$. Pengujian daya sebar bertujuan untuk melihat kemampuan penyebaran lulur krim pada permukaan kulit sehingga penyebaran zat aktif yang dikandung oleh lulur krim yang dibuat akan merata pada permukaan kulit. $^{12}$

Hasil pengujian tipe emulsi lulur krim dari F1, F2 dan F3 tidak mengalami inversi fase. Lulur krim mempunyai tipe emulsi M/A dan hal ini dapat dilihat pada uji pengenceran, yang didasarkan pada kenyataan bahwa fase luar emulsi minyak dalam air (M/A) dapat diencerkan sesuai dengan tujuan awal formulasi yaitu, untuk mendapatkan lulur krim dengan tipe minyak dalam air (M/A). Hal ini dapat di sebabkan karena jumlah fase terdispersi (minyak/lemak) yang digunakan dalam lulur krim lebih kecil dari fase pendispersi (fase air), sehingga fase minyak akan terdispersi merata ke dalam fase air dan membentuk emulsi minyak dalam air dengan bantuan emulgator. ${ }^{12}$

Tabel 4. Hasil Uji Organoleptis Lulur Krim

\begin{tabular}{|c|c|c|c|}
\hline $\begin{array}{l}\text { Lulur } \\
\text { Krim }\end{array}$ & Bentuk & Warna & Bau \\
\hline F1 & $\begin{array}{l}\text { Kental dengan granul-granul } \\
\text { halus dan lembut }\end{array}$ & Kecoklatan & $\begin{array}{c}\text { Khas ekstrak kulit bawang merah } \\
\text { dan cangkang telur ayam }\end{array}$ \\
\hline $\mathrm{F} 2$ & $\begin{array}{l}\text { Kental dengan granul-granul } \\
\text { halus dan sangat lembut }\end{array}$ & Kecoklatan & $\begin{array}{c}\text { Khas ekstrak kulit bawang merah } \\
\text { dan cangkang telur ayam }\end{array}$ \\
\hline
\end{tabular}


Jurnal Insan Farmasi Indonesia, 3(2) Desember 2020 (344-353)

Nadira Dina Mahyuna

p-ISSN 2621-3184 ; e-ISSN 2621-4032

doi: 10.36387/jifi.v3i2.579

\begin{tabular}{|c|c|c|c|}
\hline F3 & $\begin{array}{c}\text { Kental dengan granul-granul } \\
\text { halus dan sangat lembut }\end{array}$ & Kecoklatan & $\begin{array}{c}\text { Khas ekstrak kulit bawang merah } \\
\text { dan cangkang telur ayam }\end{array}$ \\
\hline
\end{tabular}

Tabel 5. Hasil Uji Homogenitas Lulur Krim

\begin{tabular}{|c|c|c|}
\hline Lulur Krim & Hasil & Keterangan \\
\hline F1 & Homogen & $\begin{array}{l}\text { Terdapat butiran halus dari serbuk cangkang telur sebagai } \\
\text { scrub }\end{array}$ \\
\hline $\mathrm{F} 2$ & Homogen & $\begin{array}{l}\text { Terdapat butiran halus dari serbuk cangkang telur sebagai } \\
\text { scrub }\end{array}$ \\
\hline F3 & Homogen & $\begin{array}{l}\text { Terdapat butiran halus dari serbuk cangkang telur sebagai } \\
\text { scrub }\end{array}$ \\
\hline
\end{tabular}

Tabel 6. Hasil Uji pH Lulur Krim

\begin{tabular}{ccc}
\hline Lulur Krim & pH & Keterangan \\
\hline F1 & 5 & \\
F2 & 5 & Memenuhi syarat range pH Kulit 4,5-6,5 \\
F3 & 5 & \\
\hline
\end{tabular}

Tabel 7. Hasil Uji Daya Sebar Lulur Krim

\begin{tabular}{cccc}
\hline Lulur Krim & $\begin{array}{c}\text { Jumlah } \\
(\mathbf{g})\end{array}$ & $\begin{array}{c}\text { Berat Beban } \\
(\mathbf{g})\end{array}$ & $\begin{array}{c}\text { Diameter Daya Sebar } \\
(\mathbf{c m})\end{array}$ \\
\hline F1 & 1 & 1,5 & 1,9 \\
F2 & 1 & 1,5 & 2,75 \\
F3 & 1 & 1,5 & 2,6 \\
\hline
\end{tabular}

\section{KESIMPULAN}

Berdasarkan hasil penelitian yang telah dilakukan, bahwa limbah kulit bawang merah (Allium cepa $\mathrm{L}$.) dan cangkang telur ayam dapat dimanfaatkan sebagai bahan pembuatan lulur krim dan emulgator span-tween 80 pada konsentrasi $2 \%$, menghasilkan stabilitas yang paling baik untuk formulasi lulur krim (F2) dari ekstrak kulit bawang merah
(Allium cepa $\mathrm{L}$ ) dan serbuk cangkang telur ayam.

\section{SARAN}

Pada penelitian selanjutnya dapat melakukan pengembangan formulasi dari lulur krim dengan variasi konsentrasi ekstrak kulit bawang merah (Allium cepa L.) dan serbuk cangkang telur ayam, sehingga dapat diketahui pada 
konsentrasi berapa yang paling bagus untuk dijadikan lulur krim.

\section{DAFTAR PUSTAKA}

1. Ningsih, Y. I. 2016. Penanganan Pasca Panen. Modul saintifikasi jamu. Fakultas Farmasi Universitas Jember, Jember.

2. Ulfa, M. 2016. Formulasi Dan Evaluasi Fisik Krim Body Scrub Dari Ekstrak Teh Hitam (Camellia Sinensis), Variasi Konsentrasi Emulgator Span-Tween 60. JK FIK UINAM. 4 (4) : 180-181.

3. Mehran. 2016. Pertumbuhan Dan Hasil Beberapa Varietas Bawang Merah (Allium Ascalonicum L) Pada Tanah Aluvial Akibat Pemberian Berbagai Dosis Pupuk Npk. J. Floratek. 11 (2) : 117.

4. Rahmadina. 2017. Pemanfaatan Limbah Cangkang Telur, Kulit Bawang dan Daun Kering Melalui Proses Sains dan Teknologi Sebagai Alternatif Penghasil Produk Yang Ramah Lingkungan. Jurnal Klorofil. 1 (1): 49.

5. Mardiah, N., dkk,. 2017. Penentuan Aktivitas Antioksidan Dari Ekstrak Kulit Bawang Merah (Allium ascalonicum L.) dengan metode DPPH. Jurnal Pharmascience. 4 (2) : 147-149.

6. Suharyanto, dkk,. 2016. Kualitas Fisik, Mikrobiologis, dan Organoleptik Telur Konsumsi yang Beredar di Sekitar Kampus IPB, Darmaga, Bogor. Jurnal Ilmu Produksi dan Teknologi Hasil Peternakan. 4 (2): 275.

7.Rahmawati, A.W., dkk. 2015. Fortikasi Kalsium Cangkang Telur Pada Pembuatan Cookis (Kajian Konsentrasi Tepung Cangkang Telur dan Baking Powder). Jurnal
Pangan dan Agroindustri. 3 (3) : 1051

8. Lestari, U., dkk. 2017. Formulasi dan Uji Sifat Fisik Lulur Body Scrub Arang Aktif Dari Cangkang Sawit (Elaeis Guineensis Jacg) Sebagai Detoksifikasi. Jurnal Sains dan Teknologi Farmasi. 19(1) : s76.

9. Wibowo, A. S., dkk. 2017. Formulasi Dan Aktivitas Anti Jamur Sediaan Krim M/A Ekstrak Etanol Buah Takokak (Solanum torvum S) Terhadap Candida albicans. Jurnal Riset Sains dan Teknologi. 1(1): 15-21.

10. Pramuditha. N. 2016. Uji Stabilitas Fisik Lulur Krim Dari Ampas Kelapa (Cocos nucifera L.) Dengan Menggunakan Emulgator Anionik Dan Nonionik. Skripsi. Fakultas Kedokteran Dan Ilmu Kesehatan Universitas Islam Negeri Alauddin, Makassar.

11. Nonci, dkk,. 2016. Formulasi Dan Uji Stabilitas Fisik Krim Susu Kuda Sumbawa Dengan Emulgator Nonionik Dan Anionik. JF FIK UINAM . 4 (4): 169-178.

12. Genatrika, E., dkk. 2016. Formulasi Sediaan Krim Minyak Jintan Hitam (Nigella sativa L.) Sebagai Antijerawat Terhadap Bakteri Propionibacterium acnes. Pharmacy. 13(2): 197. 